\title{
Pathogenic role of B cells in the development of diffuse alveolar hemorrhage induced by pristane
}

\author{
Tolga T Barker ${ }^{1}$, Pui Y Lee ${ }^{1}$, Kindra M Kelly-Scumpia ${ }^{1,2}$, Jason S Weinstein ${ }^{1}$, Dina C Nacionales ${ }^{1,2}$, Yutaro Kumagai ${ }^{3}$, \\ Shizuo Akira ${ }^{3}$, Byron P Croker ${ }^{4}$, Eric S Sobel ${ }^{1,4}$, Westley H Reeves ${ }^{1,4}$ and Minoru Satoh ${ }^{1,4}$
}

Diffuse alveolar hemorrhage is an uncommon, yet often fatal, complication of systemic lupus erythematosus (SLE). Advances in the treatment of alveolar hemorrhage have been hampered because of the heterogeneity of clinical findings and the lack of suitable animal models. A single intraperitoneal injection of pristane induces a lupus-like syndrome characterized by lupus-related autoantibodies and glomerulonephritis in non-autoimmune-prone strains of mice. In addition, C57BL/6 (B6) mice frequently develop alveolar hemorrhage within a few weeks of pristane injection. Immunopathogenesis of pristane-induced alveolar hemorrhage was investigated in the present study. Early (2-4 weeks after injection) mortality due to hemorrhage was unique to C57BL/6 and C57BL/10 strains of mice. Recruitment of the macrophages and neutrophils preceded the hemorrhage by several days, and hemorrhage started 3-7 days after pristane injection in some mice, peaked at 2 weeks (84\% in B6) and then resolved by 4 weeks in a majority of mice. Alveolar hemorrhage was independent of MyD88 (myeloid differentiation factor 88), or TLR7 pathways, in contrast to autoantibody production and glomerulonephritis, and was also independent of $\mathrm{Fc} \gamma \mathrm{R}$ or Fas. Rag $1^{-/-}$mice had a reduced prevalence of alveolar hemorrhage compared with $\mathrm{B} 6(P=0.01)$ congenics. However, T-cell receptor-deficient mice developed alveolar hemorrhage at a rate comparable to wild-type controls, whereas B6 $\lg \mu^{-1-}$ mice surprisingly had a strikingly reduced prevalence ( $7 \%$ vs $84 \%$ in $\mathrm{B} 6, P<0.0001$ ). Reconstitution of $\mathrm{B} 6 \lg \mu^{-1-}$ mice with wild-type $\mathrm{B}$ cells increased the prevalence to $50 \%(P=0.028)$. Pristane-induced alveolar hemorrhage is a useful model to study the pathogenesis and develop new therapy for this underappreciated and often life-threatening complication of SLE. Laboratory Investigation (2011) 91, 1540-1550; doi:10.1038/labinvest.2011.108; published online 1 August 2011

KEYWORDS: animal model; B cells; diffuse alveolar hemorrhage; pristane; systemic lupus erythematosus

Pulmonary manifestations in systemic lupus erythematosus (SLE) include pleural, parenchymal, vascular, and airway disease. ${ }^{1}$ Pleuritis is relatively characteristic of SLE and included in the classification criteria. Although pulmonary parenchymal manifestations are not frequently seen or pathognomonic of SLE, pneumonitis, acute respiratory distress syndrome (ARDS), diffuse alveolar hemorrhage (DAH), chronic interstitial pneumonitis, and diaphragmatic dysfunction/shrinking lung syndrome can develop. Among these, DAH is one of the most serious pulmonary complications of SLE. ${ }^{1}$ Although DAH occurs infrequently (average $1.9 \%$, reviewed in Todd and Costenbader $\left.{ }^{2}\right)^{3,4}$ in lupus patient cohorts, it is responsible for $1.5-3.7 \%$ of all SLE-associated hospital admissions, ${ }^{3,4}$ and $10-20 \%$ of mortality in SLE.
Most patients who develop DAH are young females within 5 years of diagnosis of SLE. ${ }^{2,3}$ Patients who develop DAH present with high fever, chest pain, coughing, rales, dyspnea, tachypnea, and hemoptysis. In the acute setting of a systemically ill patient, DAH is frequently difficult to differentiate from bacterial or other opportunistic pulmonary infections. ${ }^{2,4}$ Treatment for patients with DAH typically includes high doses of steroids alone or in combination with other immunosuppressive drugs and plasmapheresis. Mechanical ventilation is also required in over $50 \%$ of the cases of SLE-associated DAH. ${ }^{5}$ Despite these interventions, DAH can often recur while the patient is already on immunosuppressive therapies, and SLE-associated DAH is fatal in over $50 \%$ of cases. ${ }^{2,3,5,6}$ More effective treatment is

\footnotetext{
'Division of Rheumatology and Clinical Immunology and Center for Autoimmune Disease, Department of Medicine, University of Florida, Gainesville, FL, USA; ${ }^{2}$ Department of Surgery, University of Florida, Gainesville, FL, USA; ${ }^{3}$ Laboratory of Host Defense, World Premier International Research Center, Immunology Frontier Research Center, Osaka University, Suita, Osaka, Japan and ${ }^{4}$ Department of Pathology, Immunology, and Laboratory Medicine, University of Florida, Gainesville, FL, USA Correspondence: Professor M Satoh, MD, PhD, Division of Rheumatology and Clinical Immunology, Department of Medicine, University of Florida, P.O. Box 100221, Gainesville, FL 32610-0221, USA
}

E-mail: minoru.satoh@medicine.ufl.edu

Received 25 October 2010; revised 25 May 2011; accepted 27 May 2011 
needed, but advances in understanding the pathogenesis and testing potential new therapeutic options have been hindered by the heterogeneity of the clinical and immunopathological findings. ${ }^{2-5,7,8}$

Pristane (2,6,10,14-tetramethylpentadecane) is a hydrocarbon oil that can induce a lupus-like autoimmune syndrome that includes several of the pathognomonic characteristics of human SLE in non-autoimmune-prone strains of mice. ${ }^{9,10}$ After a single intraperitoneal (i.p.) injection of pristane, mice develop anti-U1RNP/Sm, -Su, -dsDNA, and -chromatin autoantibodies, immune complex-mediated glomerulonephritis, and arthritis. ${ }^{9-11}$ Although most of these characteristics are also present in several genetic models of SLE, the ability of pristane to induce type I interferons $\left(\right.$ IFNs) ${ }^{12-15}$ and alveolar hemorrhage $e^{16,17}$ in mice on a C57BL/6 (B6) background is unique to this chemically induced model of SLE. In this study we report that mice on the B6/B10 background frequently develop DAH, and characterize the sequence of events and the immune cells and mechanisms that are important for the development of this underappreciated and often fatal complication of SLE.

\section{MATERIALS AND METHODS \\ Mice}

Four- to six-week old A.SW, BALB/cJ, C3H/HeJ, CBA/CaJ, $\mathrm{DBA} / 1 \mathrm{~J}, \mathrm{SJL} / \mathrm{J}, \mathrm{C} 57 \mathrm{BL} / 10 \mathrm{~J}$ (B10), and C57BL/6J (B6) mice were purchased from the Jackson Laboratory (Bar Harbor, ME, USA), housed and bred in barrier cages in a conventional facility at the Malcolm Randall VA Medical Center (Gainesville, FL, USA). In addition, 4- to 6-weekold B6;129S7-Rag1 $1^{\text {tm1Mom}} / \mathrm{J}$ (B6 RAG1 ${ }^{-/-}$), B6.129P2$\mathrm{Tcrb}^{\mathrm{tm} 1 \mathrm{Mom}} \mathrm{Tcrd}^{\mathrm{Tm} 1 \mathrm{Mom}} \quad\left(\mathrm{B} 6 \mathrm{TCR}^{-l-}\right), \quad$ B6.129S2-Igh$6^{\mathrm{tm} 1 \mathrm{Cgn} / J}\left(\mathrm{~B} 6 \operatorname{Ig} \mu^{-l-}\right)$, B6.MRL-Fas ${ }^{l p r} / \mathrm{J}$ (B6 lpr), and B6 MyD88 ${ }^{-1-}$ were purchased from the Jackson Laboratory. B6.129P2-Fcerlg ${ }^{\text {tm1Ra }} \mathrm{N} 12\left(\mathrm{~B} 6 \mathrm{Fc} \gamma \mathrm{R}^{-/}\right)$were purchased from Taconic Laboratories (Hudson, NY, USA). These mice were housed and bred in barrier cages in a specific pathogen-free (SPF) facility at the Malcolm Randall VA Medical Center. B6 MyD88 ${ }^{-1-}$, Toll-like receptor (TLR) $7^{-1-}$, and TLR9 ${ }^{-1-}$ (described previously in Yamamoto et $\mathrm{al}^{18}$ ) were bred and maintained in a SPF facility at the Research Institute for Microbial Diseases at Osaka University (Osaka, Japan). At 3 to 4 months of age, mice received a single $0.5 \mathrm{ml}$ i.p. injection of sterile pristane (Sigma-Aldrich, St Louis, MO, USA). After $1,3,7,14$, or 28 days, the spleen, lungs, kidneys, and liver were harvested as described previously. ${ }^{15}$ In reconstitution studies, splenocytes from age- and sex-matched donor B6 mice were positively selected for either $\mathrm{CD} 19^{+} \mathrm{B}$ cells, $\mathrm{CD}^{+}{ }^{+} \mathrm{T}$ cells, or $\mathrm{CD} 8{ }^{+} \mathrm{T}$ cells using magnetic microbeads (Miltenyi Biotec, Auburn, CA, USA) as per the manufacturer's instructions. B6 Rag1 ${ }^{-1-}$ mice were reconstituted by intravenous injection of either 10 million splenic $\mathrm{CD} 4^{+}$ $\mathrm{T}$ cells, $\mathrm{CD} 8^{+} \mathrm{T}$ cells, or total $\mathrm{T}$ cells $\left(5 \times 10^{6}\right.$ of each $\mathrm{CD} 4^{+}$ $\mathrm{T}$ cells and $\mathrm{CD} 8^{+} \mathrm{T}$ cells). B6 Ig $\mu^{-1-}$ mice were reconstituted by intravenous injection of $20 \times 10^{6} \mathrm{CD} 19^{+} \mathrm{B}$ cells. At 3 days after receiving the transfers, the recipient $\mathrm{B} 6 \mathrm{Rag} 1^{-1-}$ and $\mathrm{B} 6$ $\operatorname{Ig} \mu^{-1-}$ mice were injected i.p. with $0.5 \mathrm{ml}$ of pristane and their organs harvested on day 14. In other experiment, the potential role of antibodies and other factors in serum was tested by transferring serum from mice with DAH. Sera were collected from two B6 mice that received pristane 2 weeks earlier and developed DAH. Serum $(200 \mu \mathrm{l})$ was intravenously injected into four naive B6 mice and their lung pathology was examined 2 weeks later. All studies were approved by the institutional animal care and use committee at the Malcolm Randall VA Medical Center.

\section{Histology}

Spleen, kidney, liver, and lung tissues were harvested and fixed in $4 \%$ paraformaldehyde overnight. The fixed tissues were embedded in paraffin, cut into $5 \mu \mathrm{m}$ sections, and stained with hematoxylin and eosin.

\section{Bronchoalveolar Lavage}

Bronchoalveolar lavage (BAL) was performed on euthanized B6 mice by making a small incision in the trachea. A $18 \mathrm{G}$ needle fitted with a blunted p20 pipette tip was attached to a $1 \mathrm{ml}$ syringe filled with $1.2 \mathrm{ml}$ of sterile Dulbecco's modification of Eagle's medium (DMEM) (Mediatech, Manassas, VA, USA). The trachea was securely clamped around the inserted $18 \mathrm{G}$ needle. The lungs were then flushed repeatedly, and the recovered fluid was collected in a $15 \mathrm{ml}$ conical tube on ice. This process was repeated as needed until a total of 3 to $4 \mathrm{ml}$ of lavage fluid was collected. The collected cells were analyzed by flow cytometry.

\section{Detection of Apoptosis}

Lung tissue sections were stained for apoptotic cells by the terminal deoxynucleotidyl transferase dUTP nick end labeling (TUNEL) assay (Apoptag Red in situ apoptosis detection kit, Millipore, Billerica, MA, USA) as per the manufacturer's instructions.

\section{Culturing Endothelial Cells with Pristane}

A human umbilical cord endothelial cell line (EaHy926, a gift from Dr F Southwick, University of Florida, Gainesville, FL, USA) was cultured in a 24 -well transwell plate $(8.0 \mu \mathrm{m}$ pore size, Costar, Corning, NY, USA) with DMEM supplemented with $10 \%$ FCS until the cells were $70 \%$ confluent. Media was removed and replaced with either fresh DMEM with 10\% FCS alone or $10 \%$ FCS that had been previously mixed with pristane. ${ }^{12}$ At three time points $(0,6$, and $24 \mathrm{~h}$ after replacement of medium), an electric current was passed over the cells and the total transepithelial electrical resistance (conductance, $1 / \Omega$ ) was measured with a STX2 manual electrode with meter (World Precision Instruments, Sarasota, FL, USA).

\section{Flow Cytometry}

The following conjugated antibodies from BD Biosciences (San Jose, CA, USA) were used: anti-CD3 complex-PE, 
anti-CD4-FITC, anti-CD5-FITC and -PE, anti-CD8-FITC, anti-CD11b-FITC and -PerCP5.5, anti-CD11c-FITC and -PE, anti-Ly6C-FITC, and anti-Ly6G-PE. Anti-CD4-APC, antiCD11b-APC, and -PerCP5.5 were purchased from eBioscience (San Diego, CA, USA). Pacific blue-conjugated antibodies to CD3 complex, CD4, CD11b, CD19, and Ly6G were purchased from Biolegend (San Diego, CA, USA). FITC, $\mathrm{PE}$, Pacific Blue, APC, and PerCP5.5-conjugated isotype controls were used to determine background fluorescence. Isolated spleen, lung, and peritoneal cells were washed with staining buffer (PBS supplemented with $0.5 \%$ bovine serum albumin, $0.05 \% \mathrm{NaN}_{3}$ ). Then, 500000 cells per well were added to a 96-well round-bottom polystyrene plate (Costar) and incubated with $25 \mu \mathrm{l}$ of Fc block. Cells were incubated with fluorescently labeled antibodies for $20 \mathrm{~min}$ at $4{ }^{\circ} \mathrm{C}$ and were then washed twice with staining buffer. The cells were fixed in $1 \%$ paraformaldehyde in $\mathrm{PBS}$, run on a Cyan ADP flow cytometer (Dako Cytomation, Carpinteria, CA, USA), and data for 20000 live cell gated events were collected for each sample with Summit acquisition software. Analyses of the data were done with Flowjo version 7.2.5 (Ashland, OR, USA).

\section{Statistical Analysis}

For differences in the prevalence of alveolar hemorrhage, Fisher's exact test was used. For the phenotypic characterization of the immune cells found within the lungs, differences between groups were analyzed by Mann-Whitney $U$-test with $P<0.05$ considered to be significant. Data are presented as mean \pm s.e.m. Statistical analyses were performed with Prism 4.0 (GraphPad Software, San Diego, CA, USA).

\section{RESULTS}

\section{Pristane Induces Pulmonary Hemorrhage in C57BL/6 Mice}

Previous work reported early mortality within the first 4 weeks after i.p. pristane injection in C57BL/6 (B6) mice, presumably due to pulmonary hemorrhage. ${ }^{16}$ Survival curves for three groups of $\mathrm{B} 6$ and $\mathrm{BALB} / \mathrm{CByJ}$ mice after pristane injection are shown in Figure $1 \mathrm{a}$ and $1 \mathrm{~b}$, respectively. Although early mortality within 4 weeks, mainly between 2 and 4 weeks, was observed in most groups of mice on the B6 background, the mortality rates varied from group to group (Figure 1a). None of the pristane-treated BALB/c mice (Figure 1b) or control PBS-treated B6 mice (data not shown) died during the same period. Mortality of various non-autoimmune-prone strains of mice during the first 4 months after pristane injection is summarized (Table 1). Death within 4 months following pristane injection was very rare in all strains except those on B6 or B10 background. Most of the mortality occurred between 2 and 4 weeks after pristane injection, and further deaths after 4 weeks were rare. A high rate of mortality was observed in SJL/J mice between 4 and 6 months after pristane injection. However, the cause of death in the SJL/J mice appeared to be from mediastinal lymphadenopathy and nephritis and not DAH, as no pulmonary hemorrhage was observed at autopsy ${ }^{19}$ (M Satoh et al, unpublished observation). Therefore, pristane induces early mortality, presumably because of alveolar hemorrhage, only in mice derived from the B6/B10 strains. Although we do not have autopsy data on all the mice that died, it seems highly likely that the mortality in these mice is due to DAH based on the high prevalence of this complication, as we show later in the time course experiment. It should also be noted that we do not have autopsy data of all strains of mice between 2 and 4 weeks when B6 mice frequently develop DAH. Thus, it is possible that some strains of mice listed in Table 1 had DAH without observed mortality.
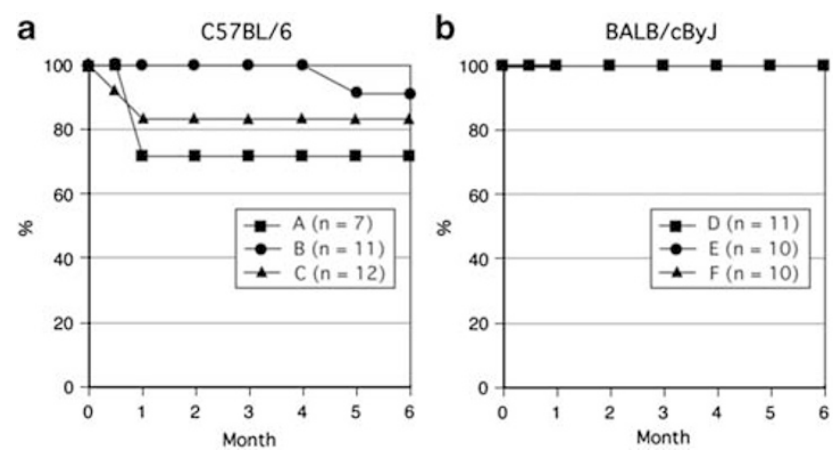

Figure 1 Survival curves of $\mathrm{C} 57 \mathrm{BL} / 6$ and $\mathrm{BALB} / \mathrm{CByJ}$ mice after pristane treatment. Survival curves for C57BL/6 (left; three groups, $n=7,11$, and 12) and BALB/CByJ (right; three groups, $n=11,10$, and 10) mice following a single $0.5 \mathrm{ml}$ intraperitoneal injection of pristane are shown.

Table 1 Mortality of non-autoimmune strains of mice following pristane injection

\begin{tabular}{lcccc}
\hline \multirow{2}{*}{ Strain } & $n$ & \multicolumn{2}{c}{ Mortality (\%) after pristane injection } \\
\cline { 3 - 5 } & & 0-2 weeks & 2-4 weeks & 4-16 weeks \\
\hline BALB/CByJ & 31 & 0 & 0 & 0 \\
BALB/CJ & 12 & 0 & 0 & 0 \\
C57BL/6J & 30 & 3 & 10 & 0 \\
B6 CH2bm12 & 12 & 0 & 42 & 0 \\
C57BL/J & 25 & 0 & 13 & 0 \\
B10.S & 15 & 0 & 12 & 0 \\
DBA/1J & 16 & 0 & 0 & 0 \\
C3H/HeJ & 16 & 0 & 0 & 0 \\
C3H/HeOuJ & 16 & 0 & 0 & 0 \\
C3HeB/FeJ & 8 & 0 & 0 & 0 \\
A.SW & 8 & 0 & 0 & 0 \\
SJL/J & 8 & 0 & 0 & 0 \\
CBA/CaJ & 24 & 0 & 0 & 0 \\
\hline
\end{tabular}




\section{Pristane-Induced Hemorrhage Is Strain and Organ Specific}

The mechanisms of pristane-induced alveolar hemorrhage are poorly understood. To determine whether the hemorrhage observed in the lungs of B6 mice was organ specific and not due to a change in general vascular permeability in vivo, $\mathrm{B} 6$ and control $\mathrm{BALB} / \mathrm{c}$ mice were injected with pristane and several organs were examined for evidence of hemorrhage. The lungs from pristane-treated $\mathrm{B} 6$ mice were filled with blood and heavily infiltrated with macrophages and neutrophils (Figure 2a, bottom left) at 2 weeks after injection. No hemorrhage or inflammatory cellular infiltrates were seen in the lungs of untreated B6 mice (Figure 2a, top left). Consistent with the lack of early mortality in BALB/c mice following i.p. injection of pristane (Table 1), the lungs of $\mathrm{BALB} / \mathrm{c}$ mice were free of any signs of hemorrhage (Figure 2a, right). We also confirmed that the hemorrhage in pristane-treated mice was limited to the lungs and not seen in the spleen, liver, and kidneys (Figure 2b), suggesting that pristane is not causing a generalized leakiness of endothelial cells in B6 mice.

As one possibility, we hypothesized that pristane may directly change the permeability of the endothelial cells in the lungs. To examine this possibility, EaHy926 cells were cultured with pristane, and conductivity was measured. The total conductance was measured immediately after changing the media and after 6 and $24 \mathrm{~h}$. At all time points, there was no difference in the total conductance across the cultured EaHy926 cells in the presence or absence of pristane (data not shown), suggesting that pristane did not directly affect permeability in human endothelial cells. Although we consider it unlikely, the possibility that pristane has different effects on murine pulmonary endothelial cells or that there may even be unique effects on B6-derived cells cannot be formally excluded.

\section{Pristane-Induced Diffuse Alveolar Hemorrhage Occurs Independently of MyD88, TLR7, FcyR Signaling, or Fas-Mediated Apoptosis}

Type I IFNs play a critical role in the pathogenesis of SLE. The expression of type I IFN correlates with active disease, certain autoantibodies to RNA-protein complexes, and increased incidence of renal involvement in human SLE. ${ }^{20,21}$ The IFN signature is also present in pristane-treated $\mathrm{B} 6$ mice, and type I IFNs are produced by Ly6 $\mathrm{C}^{\text {hi }}$ monocytes in MyD88 (myeloid differentiation factor 88)- and TLR7dependent manner. ${ }^{12}$ Additionally, the recruitment of Ly $6 \mathrm{C}^{\text {hi }}$ monocytes, Ly6 $\mathrm{C}^{\mathrm{lo}}$ macrophages, and granulocytes to the peritoneal cavity following i.p. injection of pristane depends on TLR7 and MyD88, respectively. ${ }^{12}$ Thus, whether B6 mice deficient in TLR7 or MyD88 were resistant to pristaneinduced DAH was examined 14 days after injection. Unexpectedly, both $\mathrm{MyD}^{-1-}(n=10,60 \%$ hemorrhage $)$ and $\mathrm{TLR}^{-1-}(n=4,100 \%)$ B6 mice developed DAH at prevalence similar to that of wild-type B6 mice. $\mathrm{F} c \gamma \mathrm{R}$ signaling did not play a role in the recruitment of immature monocytes and neutrophils to the peritoneal cavity following an i.p. injection of pristane. ${ }^{12}$ Although it is possible that $\mathrm{F} c \gamma \mathrm{R}$ is involved in the recruitment of inflammatory cells to the lungs, $\mathrm{B} 6 \mathrm{Fc} \gamma \mathrm{R}^{-1-}$ mice also developed $\mathrm{DAH}(n=5,80 \%$ at day 14). Based on these findings, we concluded that the induction of DAH is independent of these pathways and different from recruitment of myeloid cells to the peritoneal cavity after pristane injection. ${ }^{12}$

Although deficiencies in Fas or its ligand ( $l p r$ or gld mutations) accelerate the development of a lupus-like syndrome in mice, ${ }^{22}$ it was paradoxically found that $\mathrm{B} 6 / \mathrm{lpr}$ mice were resistant to pristane-induced lupus. ${ }^{16}$ To determine the role of Fas-mediated apoptosis in the DAH induced by pristane, lungs from B6/lpr mice 14 days after pristane injection were examined. The prevalence of DAH in pristane-treated $\mathrm{B} 6 / \mathrm{lpr}$ ( $80 \%$ hemorrhage, $n=5$ ) was not reduced $v s$ wild-type mice $(83 \%, n=24$, Figure 3$)$, unlike the production of pristane-induced anti-U1RNP/Sm autoantibodies. ${ }^{16}$ Moreover, very few apoptotic cells were detected in lung tissue by TUNEL assay before hemorrhage (data not shown). Thus, the pathways involved in pristane-induced DAH are independent of Fas-mediated apoptosis.

B1 cells are a self-renewing population of immune cells that are found predominantly in the peritoneal and pleural cavities and have an increased presence in both humans and mice that develop SLE. ${ }^{23,24}$ They produce most of the naturally occurring autoantibodies in a T-independent fashion and can also function as antigen-presenting cells (APCs), especially in response to bacterial infections. ${ }^{23}$ We examined whether the reduction of $\mathrm{B} 1$ cells in the peritoneal cavity would affect the susceptibility to DAH by depleting peritoneal B1 cells before and over the course of pristane treatment. An i.p. injection of pristane alone reduces the $\mathrm{CD} 19^{+}$ $\mathrm{CD}_{11 \mathrm{~b}}{ }^{+} \mathrm{B} 1$ cells to less than a few percent in the peritoneal cavity. ${ }^{13,15}$ The injection of distilled water into the peritoneal cavity decreased the percentage of CD19- and CD11b-positive B1 cells within the peritoneal cavity ${ }^{25}$ from $30-40 \%$ to 5-15\% (data not shown). Two-thirds of the B6 mice that had their B1 cells reduced were still susceptible to pristaneinduced DAH $(n=15,66 \%)$. The loss of peritoneal B1 cells following pristane is dramatic and their fate unclear. The role of $\mathrm{B} 1$ cells in pristane-induced DAH is not entirely conclusive, as B1 cell depletion in this experiment was incomplete. Nevertheless, this experiment was very informative, as it strongly suggests that B1 cells are not integral to the pathogenesis of pristane-induced DAH and likely unrelated to the pathogenesis of pristane-induced autoimmunity.

\section{Cellular Infiltration of the Lungs Precedes the Development of Hemorrhage}

As B6 mice start to die $\sim 2$ weeks after pristane injection and do not have further mortality after week 4 , we performed time course studies focusing on the first 4 weeks after injection to determine the sequence of pathology of DAH 
a

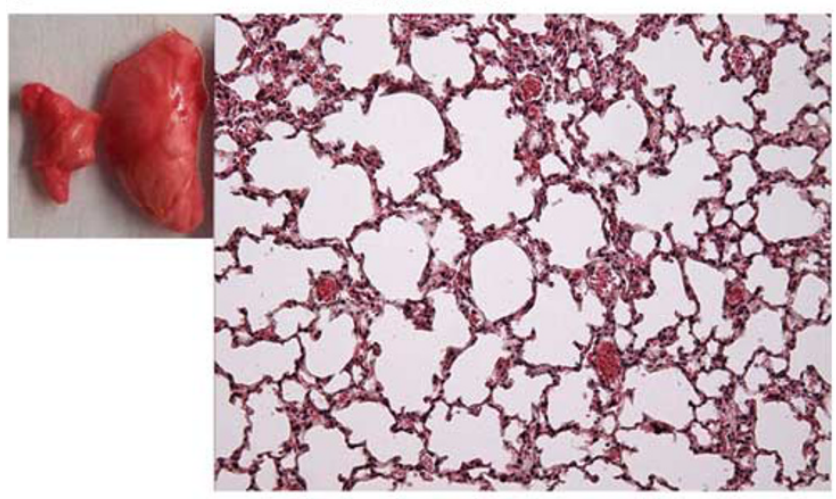

B6 2 weeks post pristane

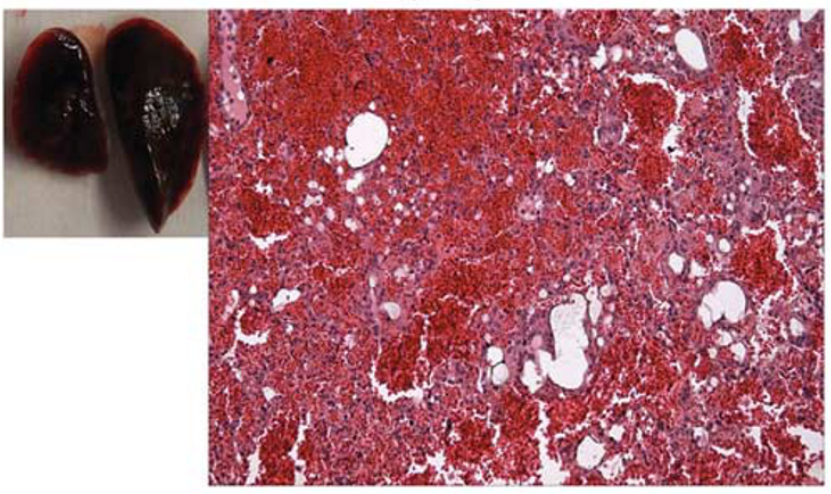

BALB/c untreated

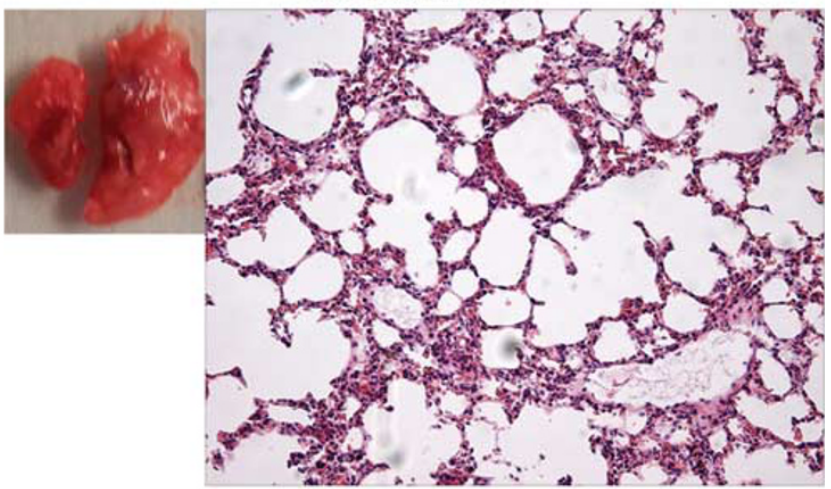

$\mathrm{BALB} / \mathrm{c} 2$ weeks post pristane

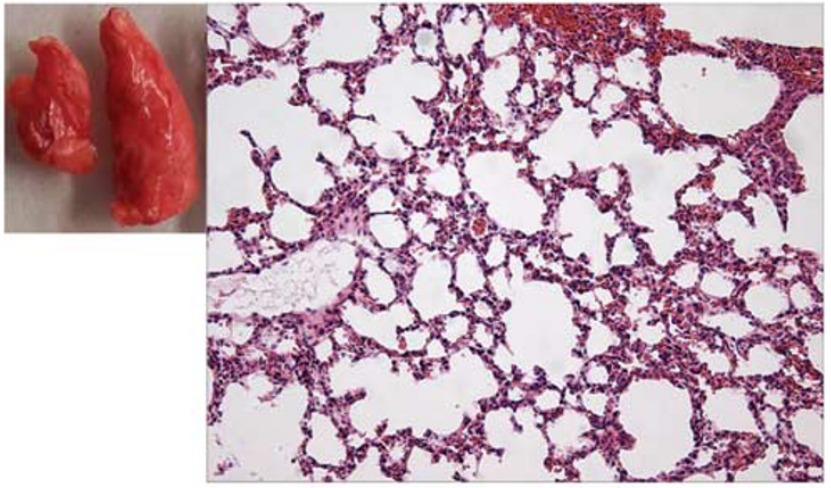

b

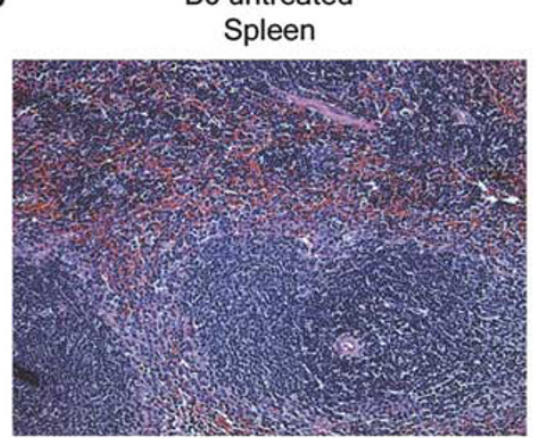

B6 2 weeks post pristane Spleen

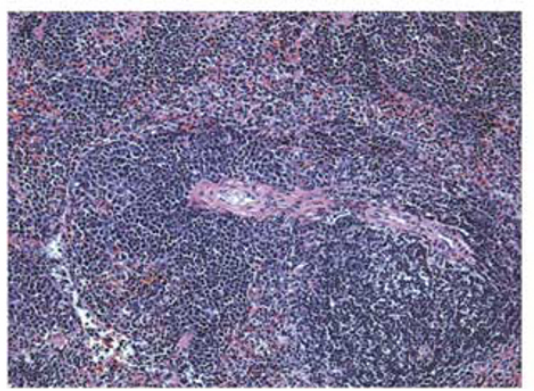

Kidney

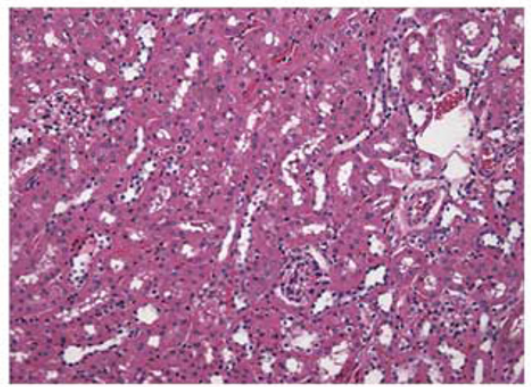

Kidney

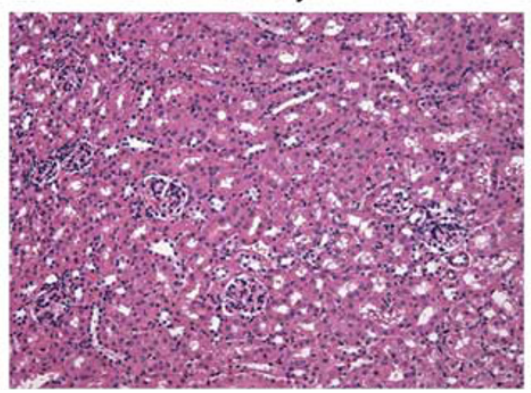

Liver

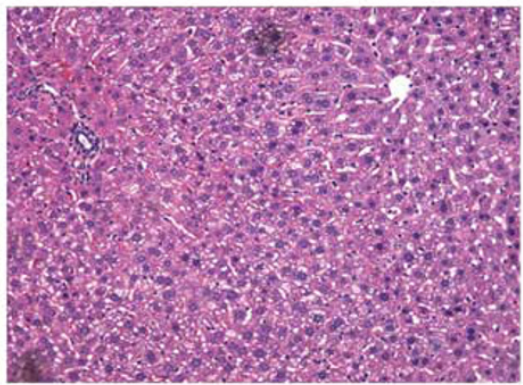

Liver

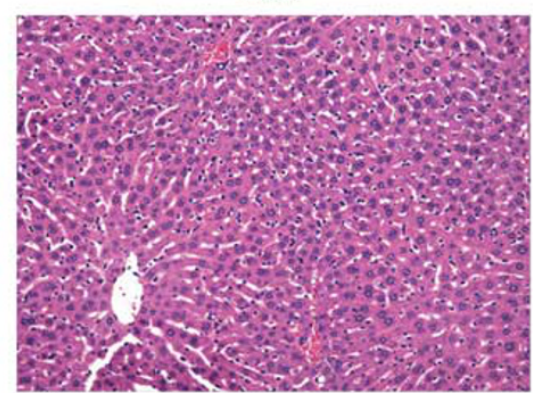

Figure 2 Pathology of lung, spleen, kidneys and liver. (a) Lung pathology of untreated vs pristane-treated C57BL/6 (B6) and BALB/C mice. Representative gross pathology and H\&E-stained tissue sections of lungs from untreated (top) or pristane-treated (bottom) C57BL/6 (left) and BALB/c (right) mice are shown ( $\times 200$ magnification). BALB/c $(n=7)$ and C57BL/6 $(n=24)$ mice received a single $0.5 \mathrm{ml}$ i.p. injection of pristane. (b) Histology of the spleen, liver, and kidneys from pristane-treated and untreated control C57BL/6 mice. Tissues were harvested from mice that received an i.p. injection of pristane 14 days earlier or left untreated ( $\times 200$ magnification, H\&E). 


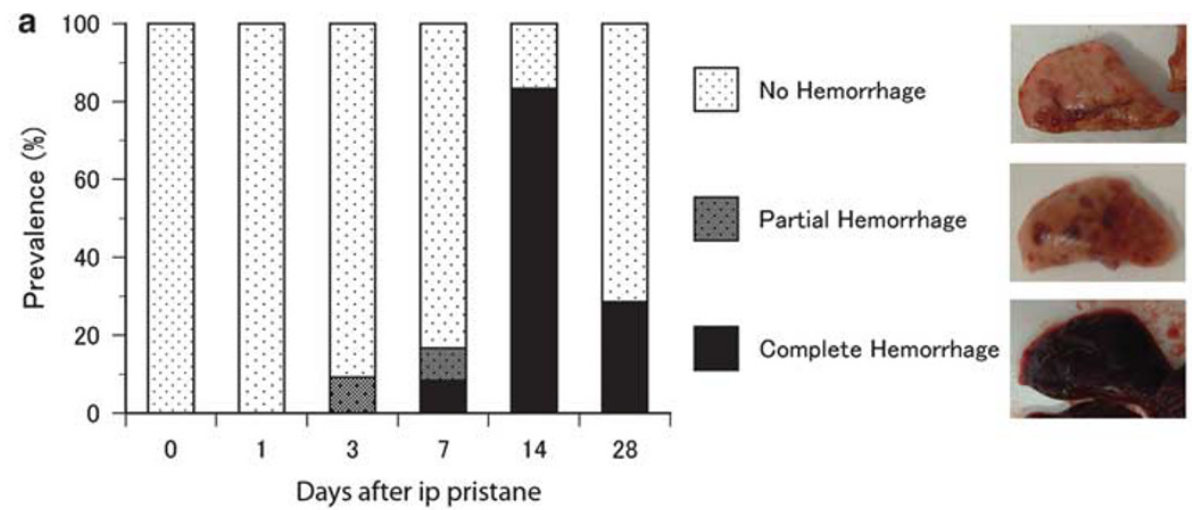

b

Untreated

Day 1

Day 3

Day 7

Day 14
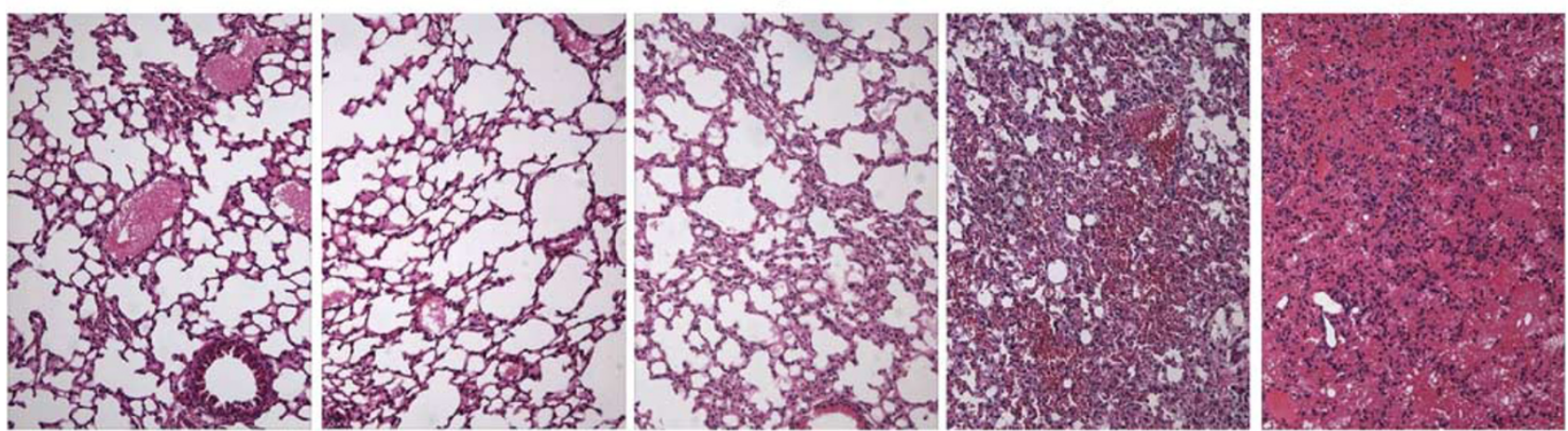

Figure 3 Time course of pristane-induced alveolar hemorrhage. (a) Incidence and types of gross pathology. C57BL/6 mice received a single intraperitoneal (i.p.) injection of pristane. Lungs were examined at day 0 (untreated, $n=7)$, day $1(n=9)$, day $3(n=11)$, day $7(n=12)$, day $14(n=24)$, and day $28(n=7)$. Lung gross pathology was classified into no hemorrhage, partial hemorrhage, and complete hemorrhage. (b) Pathology of lung tissue from pristane-treated C57BL/6 mice over time. Representative hematoxylin-eosin staining of lung tissues from pristane-treated mice at day 0 (untreated), and days 1, 3, 7, and 14 are shown (original magnification $\times 200$ ).

induced by pristane. The lungs of pristane-treated B6 mice were examined after 1, 3, 7, 14, and 28 days. Before analysis, all B6 mice were asymptomatic and were otherwise indistinguishable from their PBS-injected littermates. The first signs of alveolar hemorrhage were observed starting at 3 days after pristane injection (Figure 3a). Although over 90\% of pristane-treated B6 mice were without any signs of alveolar hemorrhage (Figure 3b), a subpopulation of B6 mice developed small yet distinct foci of hemorrhage that were uniformly distributed in all lobes of the lungs (Figure 3a). On day 7, some B6 mice developed complete/diffuse alveolar hemorrhage, whereas others had focal/partial hemorrhage. The peak incidence of DAH was at 2 weeks after pristane injection (Figure 3a); $84 \%$ of the pristane-treated B6 mice had lungs that were completely filled with blood. The incidence of DAH was reduced to $<30 \%$ at week 4 , indicating that the majority of mice that had hemorrhage at day 14 spontaneously recovered and cleared the hemorrhage from their lungs. As the lungs of human SLE patients with DAH are filled with not only erythrocytes but also proinflammatory cells such as macrophages and neutrophils, the lungs were examined histologically to determine if these cells were also being recruited to the lungs of pristane-treated B6 mice before alveolar hemorrhage. At $24 \mathrm{~h}$ after injection, no difference in the histology of the lungs was observed between pristane-treated compared with untreated B6 mice. At day 3, the lungs began to fill with proinflammatory cells (Figure $3 \mathrm{~b}$ ) and by day 7 the lungs were heavily infiltrated by inflammatory cells. It was also on day 7 that the first mouse with DAH was observed (Figure $3 \mathrm{~b}$ ). Both the hemorrhage and recruitment of inflammatory cells progressively worsened so that by day 14 , nearly all the alveolar space was replaced with erythrocytes and infiltrating immune cells (Figure 3b). Additionally, based on their morphology, the majority of the immune cells recruited to the lungs of pristane-treated $\mathrm{B} 6$ mice were identified as macrophages and neutrophils. The bleeding and accumulation of macrophages and neutrophils in the lungs of pristane-treated B6 mice in this study is consistent with the previously published work in B10 mice ${ }^{17}$ and reports of human SLE-associated 
DAH. ${ }^{4,7,26,27}$ The DAH begins as early as 1 week after the pristane injection and that the influx of macrophages and neutrophils precedes the DAH by several days.

As prevalence of DAH peaks at 2 weeks after an i.p. pristane injection, the potential role of antibodies and other factors in serum at 2 weeks in the development of DAH was tested by a serum transfer experiment. None of the four naive B6 mice that received serum from B6 mice with pristaneinduced DAH developed DAH (data not shown).

\section{Monocytes, Granulocytes, B Cells, and T Cells Accumulate Over the Course of Pristane-Induced Alveolar Hemorrhage}

Macrophages and neutrophils accumulated in the lungs of B6 mice 2 weeks after the pristane injection. To confirm the presence of these innate immune cells and to determine when and what types of immune cells accumulate in the lungs of pristane-treated B6 mice, cells in BAL fluid collected from the mice over a 14-day time course study were analyzed. The percentage of Ly6C $\mathrm{C}^{\mathrm{lo}}$ monocytes, Ly6 $\mathrm{C}^{\text {hi }}$ monocytes, and granulocytes in BAL remained constant over the first 3 days after injection of pristane (Figure $4 \mathrm{a}-\mathrm{c}$ ). At 1 week after the injection, all three populations were increased (Figure $4 a-c$ ), indicating that infiltration of these cells precedes the hemorrhage. The Ly6C $\mathrm{C}^{\text {lo }}$ and Ly6C $\mathrm{C}^{\mathrm{hi}}$ monocyte and granulocyte populations in the BAL isolated 7 and 14 days after an i.p. pristane injection appeared to be increased; however, the difference was not statistically significant (Mann-Whitney) because of high variability in individual mice and small numbers per group. When the percentage of Ly $6 \mathrm{C}^{\text {hi }}$ monocytes and granulocytes in BAL from hemorrhagic mice $(n=8)$ vs non-hemorrhagic mice $(n=3)$ was compared, the percentage in the former was significantly higher $(P=0.0121)$ than in the latter. However, the percentage of Ly6 $\mathrm{C}^{\mathrm{lo}}$ monocytes was not significantly different. The B and $\mathrm{T}$ cells in BAL also increased after days 3-7 (Figure $4 \mathrm{~d}-\mathrm{f}$ ). The percentage of $B$ cells at days 7 and 14 was significantly higher than at day $1(P=0.036$ and $P=0.021$, respectively, by Mann-Whitney). $\mathrm{CD}^{+} \mathrm{T}$ cells at days 7 and 14 were significantly increased $v s$ days 1 and $3(P=0.036$ and $P=0.028$, respectively), and $\mathrm{CD}^{+} \mathrm{T}$ cells at days 7 and 14 were higher than at day $1(P=0.036$ and $P=0.049$, respectively). Nearly all of the pristane-treated B6 mice that developed alveolar hemorrhage within 2 weeks had at least $8 \%$ of B cells in their BAL (Figure $4 \mathrm{~d}$ ). It is unclear what role $\mathrm{CD}^{+}{ }^{+} \mathrm{T}$ cells (Figure 4e) or $\mathrm{CD} 8{ }^{+} \mathrm{T}$ cells (Figure $4 \mathrm{f}$ ) play in pristane-induced alveolar hemorrhage as the number is small and the presence of T cells did not necessarily coincide with the development of DAH.

\section{B Cells Play a Pathogenic Role in Pristane-Induced Alveolar Hemorrhage}

To determine the role of $\mathrm{B}$ and $\mathrm{T}$ cells in $\mathrm{DAH}$, we examined whether B6 deficient in both these cell populations (B6 $\mathrm{Rag}^{-l-}$ ) were resistant to DAH. Half of pristane-treated B6
Rag1 $1^{-1-}$ mice developed alveolar hemorrhage (Figure 5a) at 2 weeks, indicating that $\mathrm{B}$ cells and $\mathrm{T}$ cells are not an absolute requirement. Nevertheless, prevalence of DAH in B6 $\mathrm{RAG1}^{-1-}$ mice was lower than that in wild-type B6 mice ( $P=0.01$ for complete hemorrhage, $P=0.06$ for any hemorrhage by Fisher's exact test), suggesting that B cells and/or $\mathrm{T}$ cells may accelerate the development of DAH. To clarify the role of T cells $v s$ B cells in DAH, B6 mice that were deficient in only $\mathrm{T}$ cells $\left(\mathrm{B} 6 \mathrm{TCR}^{-1-}\right.$ ) or only $\mathrm{B}$ cells (B6 $\operatorname{Ig} \mu^{-l-}$ ) were treated with pristane. Two-thirds of $\mathrm{B} 6 \mathrm{TCR}^{-1-}$ mice developed complete hemorrhage and one mouse developed partial hemorrhage (Figure 5a). In striking contrast to T-cell-deficient mice, all pristane-treated B6 $\operatorname{Ig} \mu^{-/-}$ mice, except one mouse, were resistant to alveolar hemorrhage $(P<0.0001 v s$ B6 by Fisher's exact test; Figure 5a). The prevalence of pristane-induced alveolar hemorrhage between male and female B6, B6 RAG1 ${ }^{-1-}, \mathrm{B}^{-} \mathrm{TCR}^{-1-}$, and B6 $\operatorname{Ig} \mu^{-1-}$ mice was also analyzed. Female dominance as seen in many autoimmune diseases was not observed, and the prevalence between male and female in all strains examined was not statistically different (data not shown).

The role of T cells and B cells in pristane-induced alveolar hemorrhage was examined through a series of reconstitution studies. B6 Rag1 ${ }^{-1-}$ mice were intravenously reconstituted with either wild-type $\mathrm{B} 6 \mathrm{CD} 4{ }^{+}$spleen $\mathrm{T}$ cells, $\mathrm{CD}^{+}{ }^{+}$spleen $\mathrm{T}$ cells, or a combination of both populations at 3 days before pristane treatment. It is possible that the prevalence of DAH is affected by the transfer of $\mathrm{T}$ cells, and $\mathrm{CD} 4^{+} \mathrm{T}$ cells may enhance the alveolar hemorrhage $\left(\mathrm{B} 6 \mathrm{Rag}^{-1-}+\mathrm{B} 6 \mathrm{CD}^{+}\right.$ and $\mathrm{CD} 8^{+}$vs B6 Rag1 ${ }^{-1-}+\mathrm{B} 6 \mathrm{CD} 4, P=0.04 ; \mathrm{B} 6 \mathrm{Rag} 1^{-1-}$ vs B6 Rag $1^{-1-}+\mathrm{B} 6 \mathrm{CD}^{+}, P=0.051$ by Fisher's exact test; Figure $5 \mathrm{~b})$. Reconstitution of $\mathrm{B} 6 \mathrm{Ig} \mu^{-1-}$ mice with spleen $\mathrm{CD}_{19}{ }^{+} \mathrm{B}$ cells before pristane injection dramatically increased the prevalence of alveolar hemorrhage from 7 to $50 \%\left(\mathrm{~B} 6 \operatorname{Ig} \mu^{-l-} v s \mathrm{~B} 6 \operatorname{Ig} \mu^{-l-}+\mathrm{B} 6 \mathrm{CD} 19^{+}, P=0.024\right.$ for any hemorrhage, $P=0.028$ for complete hemorrhage by Fisher's exact test; Figure $5 \mathrm{c}$ ). These results strongly suggest that the presence of $\mathrm{B}$ cells is proinflammatory in this model and that the presence of $\mathrm{T}$ cells in the absence of B cells (B6 Ig $\mu^{-1-}$ mice) is protective.

\section{DISCUSSION}

Alveolar hemorrhage is an uncommon but serious complication of SLE. However, despite many reports on case series of patients with $\mathrm{DAH}$, the pathogenesis remains to be clarified. Although the infiltration of the lungs by inflammatory cells is common and the deposition of immune complexes and capillaritis have been also described in some reports, ${ }^{4,26,28,29}$ alveolar hemorrhage can also occur in the absence of some or all of these manifestations. ${ }^{7,8}$ Advances in our understanding on the pathogenesis of alveolar hemorrhage in SLE have been hampered by the inconsistency of immunopathological and clinical findings within the literatures. Most of the information regarding tissue immunopathology is from autopsy cases, and sequential analysis of 

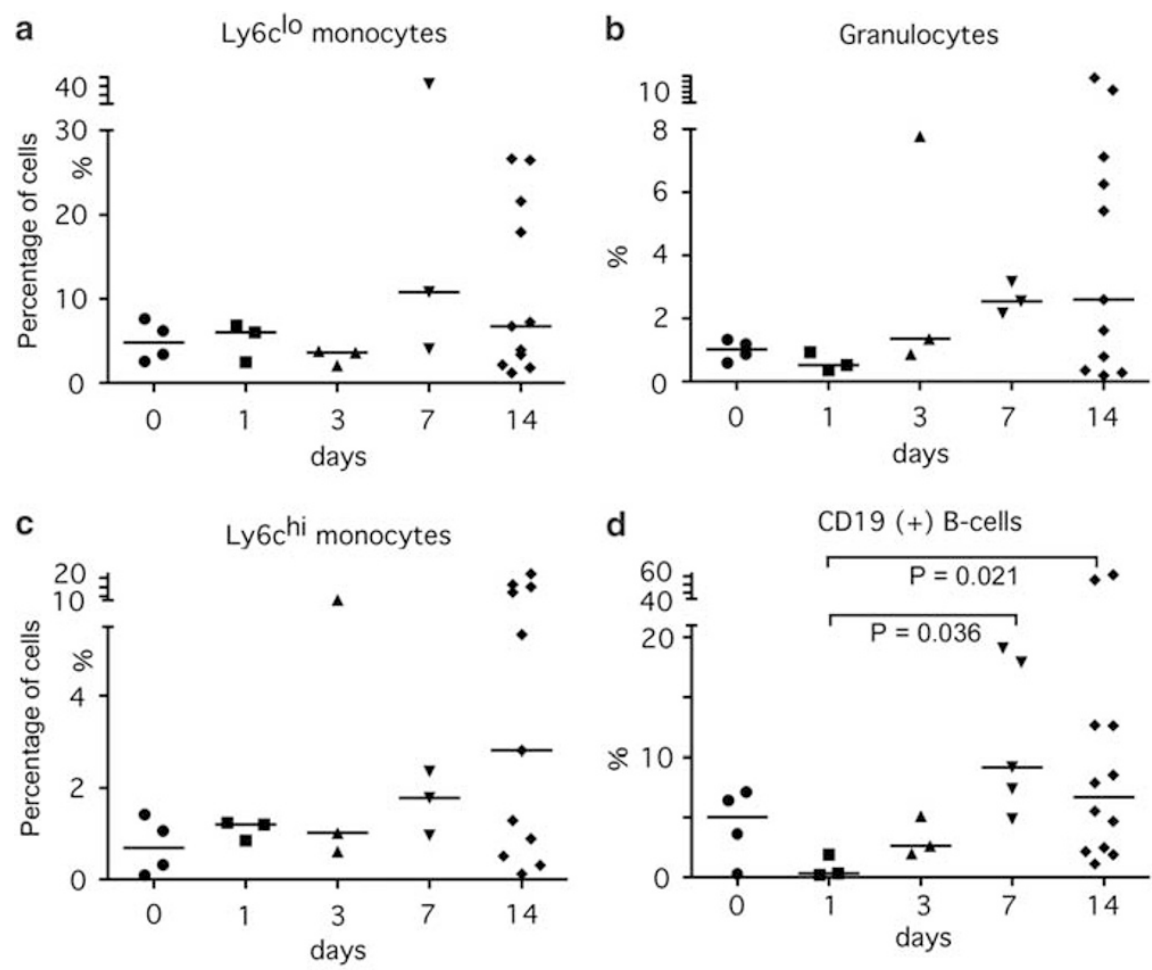

d
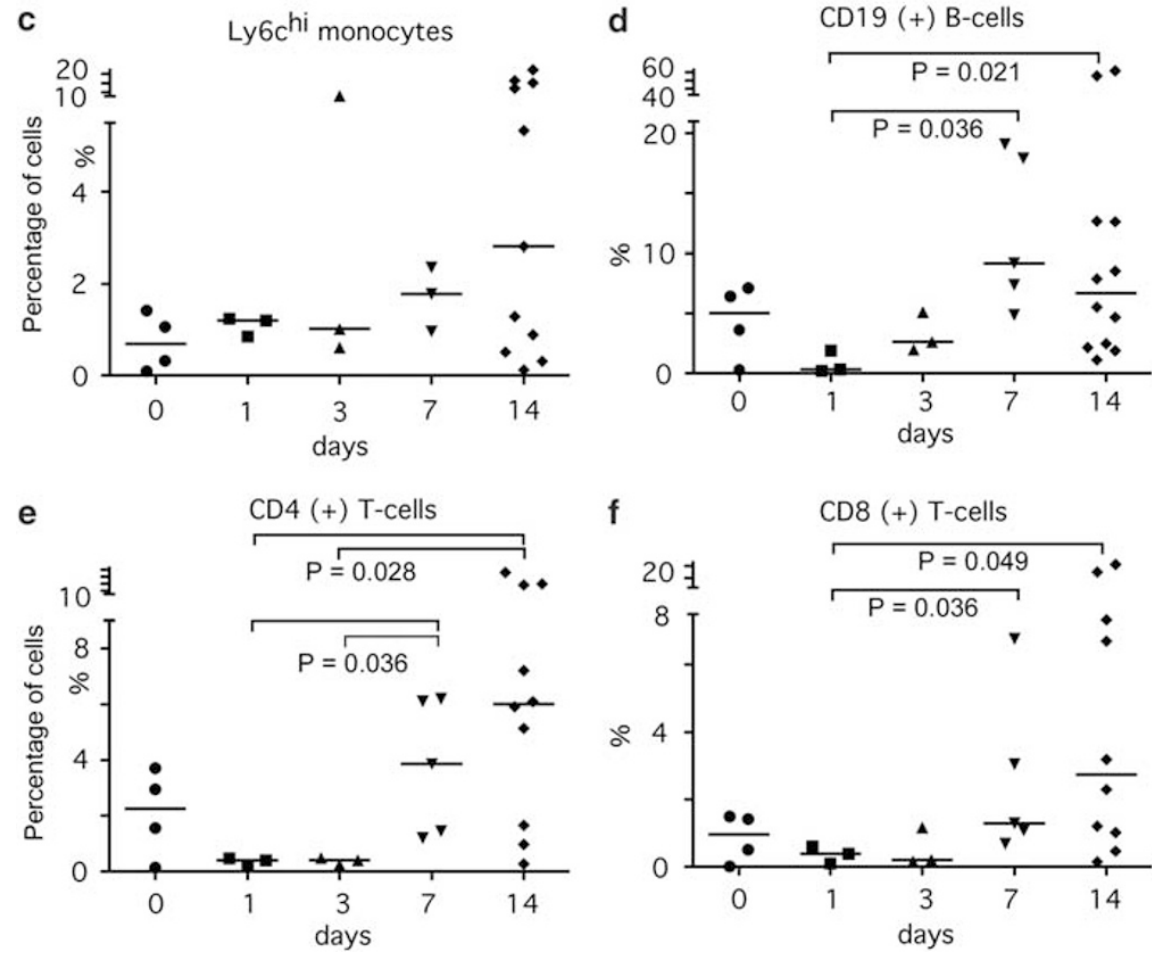

Figure 4 Flow cytometry analysis of cells in the bronchoalveolar lavage fluid of pristane-treated B6 mice. B6 mice were either left untreated (day 0, $n=4$ ) or were injected with $0.5 \mathrm{ml}$ of pristane i.p. and had their lungs lavaged after 1 day $(n=3), 3$ days $(n=3), 7$ days $(n=5)$, or 14 days $(n=11)$. Percentages of Ly6C $\mathrm{C}^{\text {lo }}$ monocytes $(\mathbf{a}), \mathrm{Ly} \mathrm{g}^{+}$granulocytes $(\mathbf{b})$, Ly6C $\mathrm{C}^{\text {hi }}$ monocytes $(\mathbf{c}), \mathrm{CD}_{19}{ }^{+}$B cells $(\mathbf{d}), \mathrm{CD}^{+}{ }^{+} \mathrm{T}$ cells $(\mathbf{e})$, and CD8 ${ }^{+} \mathrm{T}_{\text {cells }}(\mathbf{f})$ are shown. $P$-values between different time points were by Mann-Whitney U-test.

tissue is unavailable. Thus, the order and time course of immunopathological events are not known. In addition, the lack of an appropriate animal model makes it difficult to understand the immunopathogenetic mechanisms and to develop a new treatment.

A single i.p. injection of pristane induces a lupus-like syndrome that includes production of lupus-related autoantibodies, glomerulonephritis, and arthritis in several nonautoimmune-prone strains of mice. ${ }^{9-11,30}$ In addition, up to $50 \%$ of pristane-treated B6 mice die within the first month of injection because of alveolar hemorrhage, whereas this early mortality is not seen in other strains of mice (Table 1 and Figure 1). ${ }^{16}$ The present study demonstrates that the induction of pristane-induced DAH is unique to mice on the B6 background, including B10, which was originally separated from B6 mice and essentially identical in terms of genetics. This is consistent with the previous work that demonstrated that $\mathrm{B} 10$ mice were also susceptible to DAH. ${ }^{17}$ Chowdhary et $a l^{17}$ found that 2 weeks after i.p. pristane injection, the BAL fluid from B10 mice was consistently bloody and filled predominantly with macrophages and neutrophils. However, the histopathology of the lungs showed only areas of focal hemorrhage. ${ }^{17}$ Our data not only recapitulated what is seen in human patients in terms of severity of bleeding and recruitment of macrophages and neutrophils to the lungs, but we were also able to show by BAL and lung histology that inflammatory cells preceded any signs of hemorrhage by several days (Figure 4). 

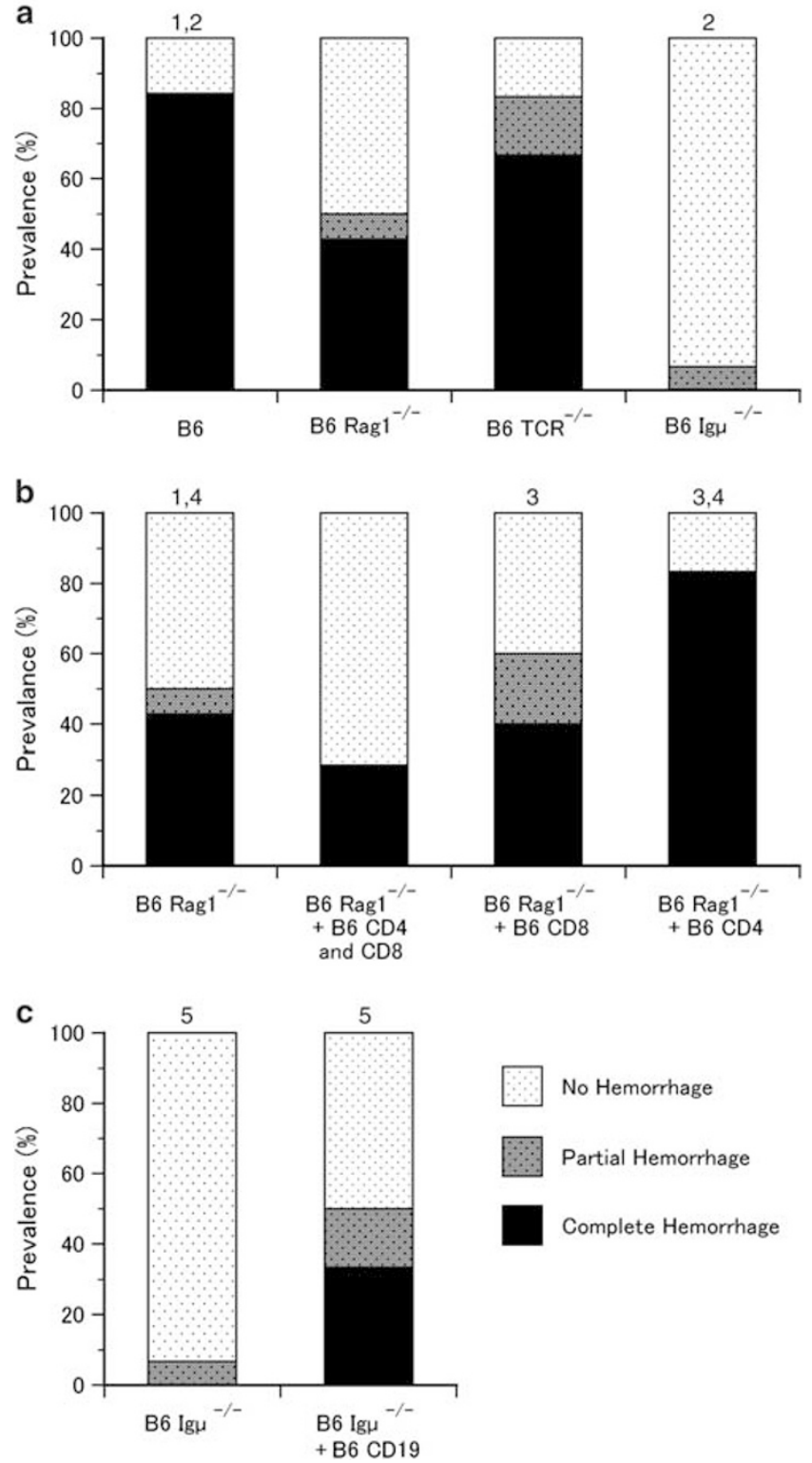

Figure 5 Role of T cells and B cells in pristane-induced alveolar hemorrhage. (a) Prevalence of alveolar hemorrhage in wild-type C57BL/6, B6 $\mathrm{RAG}^{-1-}$, $\mathrm{B} 6 \mathrm{TCR}^{-/-}$, and $\mathrm{B} 6 \lg \mu^{-/-}$mice. Lungs from C57BL/6 $(n=24)$, $\mathrm{B} 6 \mathrm{RAG}^{-1-}(n=14), \mathrm{B} 6 \mathrm{TCR}^{-1-}(n=6)$, and $\mathrm{B} 6 \lg \mu^{-1-}(n=15)$ mice 14 days after pristane treatment were examined. 1, $P=0.01$ for complete hemorrhage and $P=0.06$ for any hemorrhage. $2, \mathrm{~B} 6$ vs $\mathrm{B} 6 \lg \mu^{-/-}, P<0.0001$ by Fisher's exact test. (b) Prevalence of alveolar hemorrhage in $B 6 \mathrm{RAG}^{-1-}$ mice reconstituted with $\mathrm{T}$ cells. $\mathrm{B} 6 \mathrm{RAG} 1^{-1-}$ mice were reconstituted with $10 \times 10^{6}$ wild-type B6 splenic total T cells $(n=7), 10 \times 10^{6} \mathrm{~B}^{\mathrm{COCD}}{ }^{+}(n=5)$, or $10 \times 10^{6} \mathrm{~B}^{\mathrm{CCD}}{ }^{+}$spleen cells $(n=12), 3$ days before pristane treatment. Lungs were examined 14 days after i.p. pristane injection. 3, B6 Rag $1^{-1-}+$ $\mathrm{B} 6 \mathrm{CD}^{+}$and $\mathrm{CD}^{+}$vs $\mathrm{B} 6 \mathrm{Rag}^{-/-}+\mathrm{B} 6 \mathrm{CD}^{+}, P=0.04 ; 4, \mathrm{~B} 6 \mathrm{Rag}^{-1-}$ vs $\mathrm{B} 6 \mathrm{Rag}^{-1-}+\mathrm{B} 6 \mathrm{CD}^{+}, P=0.051$ by Fisher's exact test. (c) Effects of $\mathrm{B}$-cell reconstitution in $\mathrm{B} 6 \lg \mu^{-/-}$mice on alveolar hemorrhage. $\mathrm{B}$ cells were reconstituted in $\mathrm{B} 6 \lg \mu^{-/-}$mice by intravenous transfer of $\mathrm{CD} 19^{+}$splenic $\mathrm{B}$ cells from wild-type $B 6$ donors $\left(20 \times 10^{6} /\right.$ recipient $) 3$ days before pristane injection. B6 $\lg \mu^{-1-}(n=15)$ and B-cell-reconstituted B6 $\lg \mu^{-1-}$ mice $(n=12)$ received a single i.p. injection of pristane and lungs were examined 14 days later. 5, B6 $\lg \mu^{-1-}$ vs B6 $\lg \mu^{-1-}+\mathrm{B} 6 \mathrm{CD} 19^{+}, P=0.028$ for complete hemorrhage and $P=0.024$ for any hemorrhage by Fisher's exact test.
The production of autoantibodies to RNA-protein complexes and DNA is one of the hallmarks of the pristaneinduced model of SLE. ${ }^{9,10}$ The autoantigens are thought to be released from dead cells and can stimulate MyD88-dependent TLR signaling via TLR7 and TLR9. ${ }^{31}$ Induction of autoantibodies to snRNPs and nephritis in pristane-induced lupus was shown to be TLR7 dependent. ${ }^{12}$ MyD88 and TLR7 were also recently reported to be absolute requirements for the recruitment of monocytes and granulocytes to the peritoneal cavity following i.p. pristane injection. ${ }^{14}$ Unexpectedly, B6 mice deficient in MyD88 or TLR7 were both susceptible to pristane-induced alveolar hemorrhage, indicating that the development of DAH is not dependent on either of these signaling pathways, and thus is different from other features of lupus seen in the pristane-induced model. The susceptibility of $\mathrm{Fc} \gamma \mathrm{R}^{-1-}$ or $\mathrm{B} 6 / \mathrm{lpr}$ mice to alveolar hemorrhage was not entirely unexpected. The recruitment of $\mathrm{Ly} 6 \mathrm{C}^{\text {hi }} \mathrm{CD} 11 \mathrm{~b}^{+}$monocytes to the peritoneal cavity in response to pristane was shown to be independent of $\mathrm{Fc} \gamma \mathrm{R}$ signaling. ${ }^{14}$ Pristane exposure and defective Fas-mediated apoptosis induce lupus-associated autoantibodies by different pathways that do not appear to be synergistic. ${ }^{16}$

B1 cells are the major population of immune cells in the peritoneal and pleural cavities and have been linked to the development of autoimmune disease. ${ }^{24,25}$ As pristane is injected i.p. in this model of SLE, peritoneal B1 cells would be among the first immune cells to be exposed to this hydrocarbon oil. Peritoneal B1 cells nearly completely disappear within a few days after a single pristane injection, despite a sharp increase of serum IgM peaking at 2 weeks. ${ }^{32}$ The i.p. injections of distilled water reduced the number of B1 cells in the peritoneal cavity to $5-15 \%$, but did not affect the prevalence of DAH. Although the cause for the disappearance of B1 cells following pristane is unclear, it is known that distilled water depletes B1 cells through osmotic lysis. ${ }^{25}$ Thus, our data suggest that B1 cells are not pivotal to the development of pristane-induced DAH.

Abnormalities in B- and T-cell functions have been well described in both human and animal models of SLE. ${ }^{33}$ When the cells in BAL from pristane-treated B6 mice were examined, in addition to the monocytes and granulocytes (Figure $4 \mathrm{a}-\mathrm{c}$ ), the numbers of $\mathrm{CD}_{1} 9^{+} \mathrm{B}$ cells as well as $\mathrm{CD}^{+}$and $\mathrm{CD} 8^{+} \mathrm{T}$ cells were increased over time (Figure 4d-f). B6 Rag1 ${ }^{-/-}$mice that lack both B cells and T cells had significantly reduced prevalence of DAH compared with wild-type B6 mice (Figure 5a). The role of T cells in pristaneinduced DAH is complex. The prevalence of DAH in T-celldeficient B6 mice was similar to that of wild-type B6 mice. Additionally, when $\mathrm{B} 6 \mathrm{Rag} 1^{-1-}$ mice were reconstituted with total $\mathrm{B} 6$ splenic $\mathrm{T}$ cells, the prevalence of DAH was reduced, yet when $\mathrm{CD} 4{ }^{+} \mathrm{T}$ cells were transferred to $\mathrm{B} 6 \mathrm{Rag} 1^{-1-}$ mice, the prevalence of hemorrhage did not decrease.

$B$ cells can act protective or pathogenic in inflammation and autoimmunity. ${ }^{34-36}$ A pathologic role of $\mathrm{B}$ cells in pristane-induced DAH appeared dominant based on the rare 
occurrence of DAH in B6 Ig $\mu^{-1-}$ mice (Figure $5 \mathrm{a}$ and $\mathrm{b}$ ). The increased susceptibility of $\mathrm{B} 6 \operatorname{Ig} \mu^{-1-}$ mice reconstituted with wild-type $\mathrm{CD}_{19}{ }^{+}$splenocytes before injecting them with pristane further confirmed the pathologic role of B cells in this model. The accumulation of inflammatory cells and hemorrhage starts within a week of pristane injection, when an increase of serum IgG is not apparent and is too early for an adaptive B-cell response. In the absence of B cells, very few immune cells were found in the lungs of pristane-treated B6 mice (data not shown). Also, no immune complexes or complement deposition was detected in the lungs of pristanetreated B6 mice (data not shown). Although this aspect was not extensively examined, transfer of serum from mice with DAH to naive mice did not induce DAH. All these data suggest that the $\mathrm{B}$ cells contribute to the DAH via nonantibody-mediated functions such as production of proinflammatory cytokines and chemokines to recruit monocytes and neutrophils or via antigen-presentation function and costimulation of other immune cells. ${ }^{34,37}$ It remains to be clarified whether B cells play a direct or indirect role in the recruitment of the inflammatory cells to the lungs and initiation of hemorrhage in this model.

The proinflammatory role of B cells in DAH, suggested in the current study, is also consistent with recent reports on successful treatment of cases of DAH in SLE by B-cell depletion therapy using Rituxan (Rituximab). ${ }^{38-40}$ As the effects of Rituximab are rapid, far before any possible effect on the levels of circulating autoantibodies, it has been suggested that the main mechanism of work is via control of antigen-presenting function, B-cell cytokine stimulation, and T-cell activation. ${ }^{40}$ Although targeting B cells seems to be a potentially attractive therapy, they represent a minor population found within the hemorrhagic lungs of both SLE patients and B6 mice. Nevertheless, B-cell-depleting therapy may be considered a potential treatment option based on the pathogenic role of B cells shown in the current study and a few reports of successful treatment of alveolar hemorrhage in SLE.,238-40

In summary, the present study establishes the pristaneinduced DAH in B6 mice as a suitable animal model to study the pathogenesis of alveolar hemorrhage. This model exhibits immunopathologic features that closely resemble those seen in human SLE patients and will be useful in obtaining a better understanding of the pathogenesis of DAH. Nevertheless, it should be noted that most mice survive and recover from DAH in this model, different from DAH in human SLE. This could be a potential limitation when testing new treatment for DAH using this model. Based on our data, we would propose the following model. The i.p. injection of pristane provokes a relatively rapid and potent response by cells of the innate immune system in genetically susceptible B6 or B10 mice, but the pathways stimulating these cells are distinct from those regulating the migration of immature monocytes to the peritoneal cavity. The severity and recovery from this insult by the innate immune system is dependent upon the adaptive immune response, with $\mathrm{B}$ cells providing proinflammatory APCs that enhance and prolong the response. $\mathrm{T}$ cells play a more complicated role, with a normal regulatory $\mathrm{T}$-cell response being blunted or delayed by the proinflammatory $\mathrm{B}$ cells. The basis for the greater susceptibility of B6/B10 mice remains unclear and could be due to cells of hematopoietic or non-hematopoietic origin. Our model leads to a number of testable hypotheses that will be the target of future experiments that should shed light on a lethal and poorly understood complication of SLE.

\section{ACKNOWLEDGEMENTS}

We thank Molecular Pathology and Immunology core at the University of Florida as well as Dr Liyang Liu, Dr Erbin Dai, and Dr Alexandra Lucas for expert assistance with the histological studies and Mr Ed Butfiloski for expert assistance regarding the flow cytometry. This work was supported by research grants from Lupus Foundation of America, and R01-AR44731 and T32-007603 from the US Public Health Service, and by generous gifts from Lupus Link and Mr Lewis M Schott to the University of Florida Center for Autoimmune Disease.

\section{DISCLOSURE/CONFLICT OF INTEREST}

The authors declare no conflict of interest.

1. Kamen DL, Strange C. Pulmonary manifestations of systemic lupus erythematosus. Clin Chest Med 2010;31:479-488.

2. Todd DJ, Costenbader KH. Dyspnoea in a young woman with active systemic lupus erythematosus. Lupus 2009;18:777-784.

3. Santos-Ocampo AS, Mandell BF, Fessler BJ. Alveolar hemorrhage in systemic lupus erythematosus: presentation and management. Chest 2000;118:1083-1090.

4. Zamora MR, Warner ML, Tuder R, et al. Diffuse alveolar hemorrhage and systemic lupus erythematosus. Clinical presentation, histology, survival, and outcome. Medicine (Baltimore) 1997;76:192-202.

5. Badsha $\mathrm{H}$, Teh $\mathrm{CL}$, Kong $\mathrm{KO}$, et al. Pulmonary hemorrhage in systemic lupus erythematosus. Semin Arthritis Rheum 2004;33:414-421.

6. Schwab EP, Schumacher Jr HR, Freundlich B, et al. Pulmonary alveolar hemorrhage in systemic lupus erythematosus. Semin Arthritis Rheum 1993;23:8-15.

7. Desnoyers MR, Bernstein S, Cooper AG, et al. Pulmonary hemorrhage in lupus erythematosus without evidence of an immunologic cause. Arch Intern Med 1984;144:1398-1400.

8. Castaneda S, Herrero-Beaumont G, Aguado JM, et al. Pulmonary hemorrhage in lupus erythematosus without evidence of an immunologic cause. Arch Intern Med 1985;145:2128-2129.

9. Satoh M, Kumar A, Kanwar YS, et al. Anti-nuclear antibody production and immune-complex glomerulonephritis in BALB/c mice treated with pristane. Proc Natl Acad Sci USA 1995;92:10934-10938.

10. Satoh $M$, Reeves WH. Induction of lupus-associated autoantibodies in $\mathrm{BALB} / \mathrm{C}$ mice by intraperitoneal injection of pristane. J Exp Med 1994;180:2341-2346.

11. Wooley PH, Seibold JR, Whalen JD, et al. Pristane-induced arthritis. The immunologic and genetic features of an experimental murine model of autoimmune disease. Arthritis Rheum 1989;32:1022-1030.

12. Lee PY, Kumagai Y, Li Y, et al. TLR7-dependent and FcgammaRindependent production of type I interferon in experimental mouse lupus. J Exp Med 2008;205:2995-3006.

13. Lee PY, Li Y, Kumagai Y, et al. Type I interferon modulates monocyte recruitment and maturation in chronic inflammation. Am J Pathol 2009;175:2023-2033.

14. Lee PY, Weinstein JS, Nacionales DC, et al. A novel type I IFN-producing cell subset in murine lupus. J Immunol 2008;180:5101-5108.

15. Nacionales DC, Kelly KM, Lee PY, et al. Type I interferon production by tertiary lymphoid tissue developing in response to $2,6,10,14$ tetramethyl-pentadecane (pristane). Am J Pathol 2006;168:1227-1240.

16. Satoh $M$, Weintraub JP, Yoshida $H$, et al. Fas and Fas ligand mutations inhibit autoantibody production in pristane-induced lupus. J Immunol 2000;165:1036-1043. 
17. Chowdhary VR, Grande JP, Luthra HS, et al. Characterization of haemorrhagic pulmonary capillaritis: another manifestation of Pristane-induced lupus. Rheumatology (Oxford) 2007:46:1405-1410.

18. Yamamoto M, Sato $S$, Hemmi $H$, et al. Role of adaptor TRIF in the MyD88-independent toll-like receptor signaling pathway. Science 2003;301:640-643.

19. Satoh $M$, Hamilton $K$, Ajmani $A$, et al. Autoantibodies to ribosomal $P$ antigens with immune complex glomerulonephritis in SJL mice treated with pristane. J Immunol 1996;157:3200-3206.

20. Kirou KA, Lee C, George $S$, et al. Activation of the interferon-alpha pathway identifies a subgroup of systemic lupus erythematosus patients with distinct serologic features and active disease. Arthritis Rheum 2005;52:1491-1503.

21. Zhuang $\mathrm{H}$, Narain S, Sobel $\mathrm{E}$, et al. Association of anti-nucleoprotein autoantibodies with upregulation of Type I interferon-inducible gene transcripts and dendritic cell maturation in systemic lupus erythematosus. Clin Immunol 2005;117:238-250.

22. Nagata S, Suda T. Fas and Fas ligand: Ipr and gld mutations. Immunol Today 1995;16:39-43.

23. Montecino-Rodriguez E, Dorshkind K. New perspectives in B-1 B cell development and function. Trends Immunol 2006;27:428-433.

24. Hardy RR. B-1 B cells: development, selection, natural autoantibody and leukemia. Curr Opin Immunol 2006;18:547-555.

25. Murakami M, Yoshioka $H$, Shirai $T$, et al. Prevention of autoimmune symptoms in autoimmune-prone mice by elimination of B-1 cells. Int Immunol 1995;7:877-882.

26. Swigris JJ, Fischer A, Gillis J, et al. Pulmonary and thrombotic manifestations of systemic lupus erythematosus. Chest 2008;133:271-280.

27. Churg A, Franklin W, Chan KL, et al. Pulmonary hemorrhage and immune-complex deposition in the lung. Complications in a patient with systemic lupus erythematosus. Arch Pathol Lab Med 1980;104:388-391.

28. Mintz G, Galindo LF, Fernandez-Diez J, et al. Acute massive pulmonary hemorrhage in systemic lupus erythematosus. J Rheumatol 1978;5: $39-50$.
29. Myers JL, Katzenstein AA. Microangiitis in lupus-induced pulmonary hemorrhage. Am J Clin Pathol 1986;85:552-556.

30. Satoh M, Richards HB, Shaheen VM, et al. Widespread susceptibility among inbred mouse strains to the induction of lupus autoantibodies by pristane. Clin Exp Immunol 2000;121:399-405.

31. Vollmer J, Tluk S, Schmitz C, et al. Immune stimulation mediated by autoantigen binding sites within small nuclear RNAs involves Toll-like receptors 7 and 8. J Exp Med 2005;202:1575-1585.

32. Hamilton KJ, Satoh M, Swartz J, et al. Influence of microbial stimulation on hypergammaglobulinemia and autoantibody production in pristane-induced lupus. Clin Immunol Immunopathol 1998;86: 271-279.

33. Kyttaris VC, Juang YT, Tsokos GC. Immune cells and cytokines in systemic lupus erythematosus: an update. Curr Opin Rheumatol 2005; 17:518-522.

34. Lund FE, Randall TD. Effector and regulatory B cells: modulators of CD4(+) T cell immunity. Nat Rev Immunol 2010;10:236-247.

35. Anderton SM, Fillatreau S. Activated B cells in autoimmune diseases: the case for a regulatory role. Nat Clin Pract Rheumatol 2008;4: 657-666.

36. Haas KM, Watanabe $R$, Matsushita $T$, et al. Protective and pathogenic roles for $B$ cells during systemic autoimmunity in NZB/W F1 mice. J Immunol 2010;184:4789-4800.

37. Browning JL. B cells move to centre stage: novel opportunities for autoimmune disease treatment. Nat Rev Drug Discov 2006;5:564-576.

38. Nellessen CM, Poge U, Brensing KA, et al. Diffuse alveolar haemorrhage in a systemic lupus erythematosus patient successfully treated with rituximab: a case report. Nephrol Dial Transplant 2008;23: 385-386.

39. Pinto LF, Candia L, Garcia P, et al. Effective treatment of refractory pulmonary hemorrhage with monoclonal anti-CD20 antibody (rituximab). Respiration 2009;78:106-109.

40. Narshi $C B$, Haider $S$, Ford $C M$, et al. Rituximab as early therapy for pulmonary haemorrhage in systemic lupus erythematosus. Rheumatology (Oxford) 2010;49:392-394. 